\title{
Structural and magnetic Properties of Mn, Co, Ni doped ZnO Nanocrystals
}

\author{
Tamirat Tibebu ${ }^{1}$, Raghavender A. ${ }^{1^{\star}}$, Kebede Legesse Kabeta ${ }^{1}$, Anjaneyulu $\mathrm{T}^{2}$ \\ and Melkamu Biyane Regasa ${ }^{3}$
}

\author{
${ }^{1}$ Department of Physics, College of Natural and Computational Sciences, Wollega University, \\ Post Box No: 395, Nekemte, Ethiopia
}

${ }^{2}$ Department of Physics, Narasaraopet Engineering College, Narasaraopet - 522 601, Andhra Pradesh, India

${ }^{3}$ Department of Chemistry, College of Natural and Computational Sciences, Wollega University, Post Box No: 395, Nekemte, Ethiopia

\begin{tabular}{|c|c|}
\hline Abstract & Article Information \\
\hline \multirow{5}{*}{$\begin{array}{l}\text { ZnO is one of the most important semiconductor material for research. It is abundant, cost } \\
\text { effective, non-toxic and also it is used in many bio-medical applications. The transition } \\
\text { metal(TM) such as manganese (Mn), cobalt (Co) and nickel (Ni) doped zinc oxide (ZnO) } \\
\text { nanocrystals are promising candidates for variety of practical application due to their spin of } \\
\text { electron that lead to new magnetic, optical and transport properties. TM doped ZnO } \\
\text { nanocrystals were synthesized using co-precipitation technique. The structural and magnetic } \\
\text { properties were investigated using X-ray diffraction (XRD), scanning electron microscope } \\
\text { (SEM), Fourier transform infrared spectroscopy (FTIR) and vibrating sample magnetometer } \\
\text { (VSM) measurements. The XRD of Mn-doped ZnO nanocrystals shows hexagonal structure. } \\
\text { The crystal size from the XRD was observed to be } 10 \mathrm{~nm} \text {. FTIR spectra shows strong } \\
\text { absorption peaks between } 200-600 \mathrm{~cm}^{-1} \text { as a characteristic bands due to the metal ions. The } \\
\text { TM doped ZnO nanocrystals shows weak ferromagnetic properties at room temperature. It is } \\
\text { well known that, ZnO has large band gap energy about } 3.3 \text { ev which only absorb light within UV } \\
\text { region. TM doped ZnO nanocrystals have very good photo catalytic activities, therefore in our } \\
\text { further research work, we plan to investigate different optical properties of these materials. } \\
\text { Copyright@2015 STAR Journal, Wollega University. All Rights Reserved. }\end{array}$} & $\begin{array}{l}\text { Article History: } \\
\text { Received : } 12-01-2015 \\
\text { Revised }: 20-03-2015 \\
\text { Accepted }: 23-03-2015\end{array}$ \\
\hline & $\begin{array}{l}\text { oras: } \\
\text { rystals } \\
\text { ecipitation technique } \\
\text { ped } \mathrm{ZnO} \\
\text { ural properties } \\
\text { etic properties }\end{array}$ \\
\hline & \\
\hline & \\
\hline & \\
\hline
\end{tabular}

\section{INTRODUCTION}

$\mathrm{ZnO}$ is one of the semiconductor materials that is widely used and is key element in many industrial manufacturing process including paint, cosmetics, plastics, battery, electrical equipment, rubber, soap, textile, floor covering and etc. $\mathrm{ZnO}$ is the material with a great variety of technological application such as surface acoustic wave devices, piezoelectric transducer, optical wave guides, gas sensor, spin functional devices and ultraviolet light emitter. TM doped dilute magnetic semiconductors (DMS) such as $\mathrm{ZnO}$ has recently attracted increasing research attention due to their potential use in spintronic devices (Pearton et al., 2003; Hong et al., 2005; Hong et al., 2007 and Hong et al., 2005). Ferromagnetic properties in TM doped $\mathrm{ZnO}$ nanoparticles and thin films have been investigated by several research groups (Martinez et al., 2005; Sato et al., 2002; Hong et al., 2005 and Hong et al., 2007 etc.). It has been addressed that the origin of ferromagnetism in TM doped $\mathrm{ZnO}$ nanoparticles and thin films was due to the introdution of defects during the synthesis process and growth of the films. But, still the origin of ferromagnetism is in debate. Therefore, in order to understand the role of transition metal ions doping in $\mathrm{ZnO}$ nanoparticles and to investigate the structural and magnetic properties we carried this present work.

\section{MATERIALS AND METHODS}

$\mathrm{Mn}, \mathrm{Co}$ and $\mathrm{Ni}$ doped $\mathrm{ZnO}$ nanoparticles were synthesized using coprecipitation technique (Raghavender et al., 2011 and Berhanu et al., 2014). The AR grade sodium hydroxide $(\mathrm{NaOH})$, zinc nitrate hexhydrate $\left(\mathrm{Zn} \quad\left(\mathrm{NO}_{3}\right)_{2} 6 \mathrm{H}_{2} \mathrm{O}\right)$, manganese (II) nitrate hydrate $\left(\mathrm{Co}\left(\mathrm{NO}_{3}\right)_{2} .6 \mathrm{H}_{2} \mathrm{O}\right)$, cobalt nitrate hex hydrate (Co $\left.\left(\mathrm{NO}_{3}\right)_{2} 6 \mathrm{H}_{2} \mathrm{O}\right)$ and nickel nitrate $\left.\left(\mathrm{Ni}\left(\mathrm{NO}_{3}\right)_{2}\right) \cdot 6 \mathrm{H}_{2} \mathrm{O}\right)(98 \%)$ were used as starting materials. The metal nitrates were dissolved together in minimum amount of deionized water to get a clear solution. $\mathrm{NaOH}$ solution was added drop by drop to metal nitrates solution under vigorous stirring. The precipitation occurred immediately to change the reaction solution to dark brown. The entire reaction was carried out at $75{ }^{\circ} \mathrm{C}$ for $2 \mathrm{~h}$. The $\mathrm{pH}$ of the solution was varied by $\mathrm{NaOH}$. The resulting precipitates were washed with deionized water and ethanol several times. The resulting precipitates was dried at $200{ }^{\circ} \mathrm{C}$ for $3 \mathrm{~h}$. The structural characterization of precipitates powders was carried out using Philips (France) X-ray diffraction (XRD) system with $\mathrm{Ni}$ filter using $\mathrm{Cu}-\mathrm{Ka}$ radiation (wave length $\lambda=1.54 \mathrm{~A}^{\circ}$ ). The morphology was verified using FEI Quanta (USA) FEG 200 High Resolution Scanning Electron Microscope (HR-SEM). Further structure was confirmed by ABB Bomem MB 102 (Canada) infrared (FTIR) spectrometer. 
Tamirat Tibebu et alo,

The samples were mixed with $\mathrm{KBr}$ and made in the form of pellets for IR transmission measurements. Room temperature magnetic properties were investigated using Lakeshore (USA) vibrating sample magnetometer (VSM 7410).

\section{RESULTS AND DISCUSSIONS}

Figure.1 shows the typical X-ray diffraction patterns of Mn-doped ZnO nanoparticles. XRD spectra shows the hexagonal structure. The extracted cell parameters of the wurtzite-like phase of sample shows $a=3.253 \AA$ and $c=$ $5.214 \AA$. These lattice values are very close to the undoped $\mathrm{ZnO}$. The sharp intense peaks of $\mathrm{ZnO}$ confirms the good crystalline nature of $Z_{0.9} \mathrm{Mn}_{0.1} \mathrm{O}$ and the peaks originated from (100), (002), (101), (102), (110), (103), (200),(112), (201),(004) and (202) peaks. The particle size calculated by Debye Scherer's formula was observed to be $10 \mathrm{~nm}$. The broad peaks of the synthesized sample confirms very narrow particle size. Except a small amount of un-reacted $\mathrm{ZnO}$, the sample shows the peaks corresponding to $\mathrm{Zn}_{0.9} \mathrm{Mn}_{0.1} \mathrm{O}$.

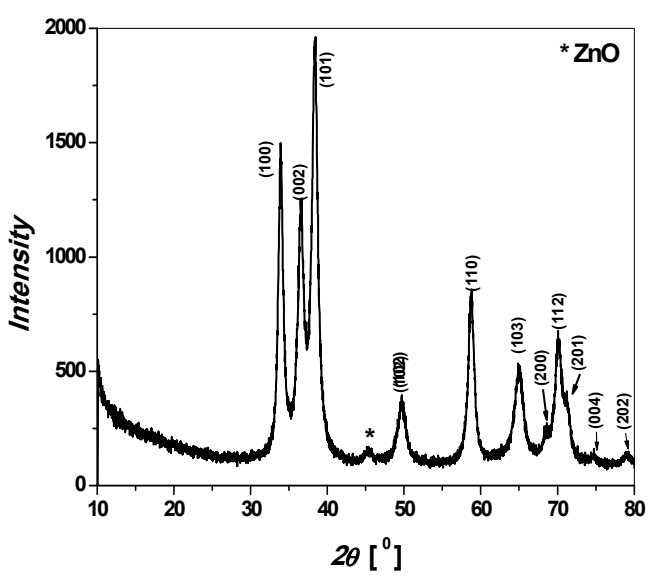

Figure 1: X-ray diffraction patterns of $\mathrm{Zn}_{0.9} \mathrm{Mn}_{0.1} \mathrm{O}$ nanoparticles

The nanoparticles nature of the $2 \mathrm{n}_{0.9} \mathrm{Mn}_{0.1} \mathrm{O}$ was confirmed using the SEM analysis. As the particle size confirmed by the XRD was about $10 \mathrm{~nm}$, due to nanocrystalline nature and narrow particle size, the SEM magnification was not sufficient to see the particle size distribution very clearly. However, as observed from Figure 2 the SEM image shows very narrow particle size.

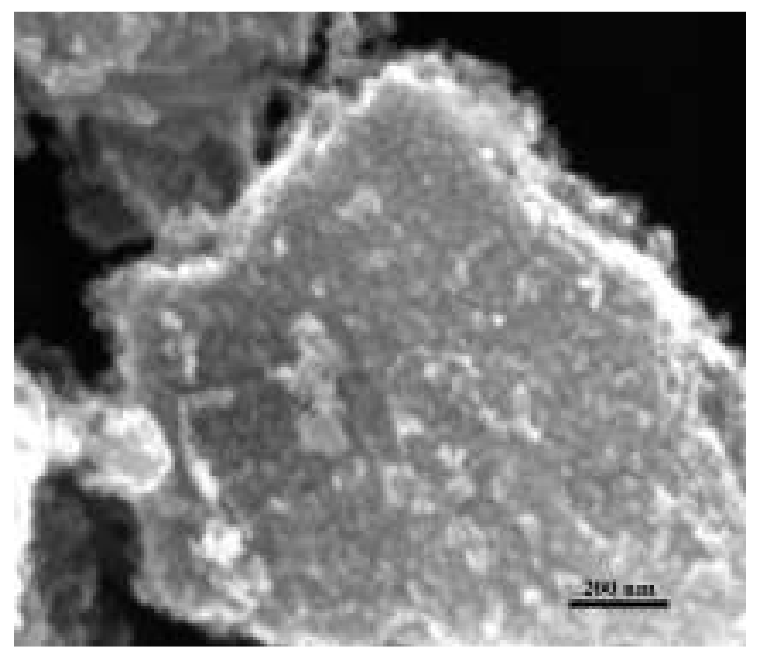

Figure 2: SEM image of $Z \mathrm{n}_{0.9} \mathrm{Mn}_{0.1} \mathrm{O}$ nanoparticles
Sci. Technol. Arts Res. J., Jan-March 2015, 4(1): 88-90

The structural properties of $\mathrm{Mn}, \mathrm{Co}$ and $\mathrm{Ni}$ doped $\mathrm{ZnO}$ nanoparticles were further investigated using IR analysis. Figure. 3 shows the IR spectra of $\mathrm{Zn}_{0.9} \mathrm{Mn}_{0.1} \mathrm{O}, \mathrm{Zn}_{0.9} \mathrm{Co}_{0.1} \mathrm{O}$ and $\mathrm{Zn}_{0.9} \mathrm{Ni}_{0.1} \mathrm{O}$ nanoparticles. As observed from Figure. 3 , there is strong absorption peak between $200-600 \mathrm{~cm}^{-1}$ as characteristic band due to the metal ions doped in $\mathrm{ZnO}$ (Wang et al., 1999). $\mathrm{Zn}_{0.9} \mathrm{Mn}_{0.1} \mathrm{O}, \quad \mathrm{Zn}_{0.9} \mathrm{CO}_{0.1} \mathrm{O}$ and $\mathrm{Zn}_{0.9} \mathrm{Ni}_{0.1} \mathrm{O}$ nano crystals have strong vibrational mode around $500 \mathrm{~cm}^{-1}$ which are assigned to the stretching vibrations of $\mathrm{ZnO}$. The vibrational band in $\mathrm{ZnO}$ changes due to $\mathrm{Mn}$, Co and $\mathrm{Ni}$ doping. These bands are the characteristics bands corresponding to the synthesized materials. Apart from the main vibrational bands, the bands due to $\mathrm{H}_{2} \mathrm{O}$, nitrates and carboxylic groups are not present in the IR spectra revealing the phase formation and the purity of the synthesized materials.

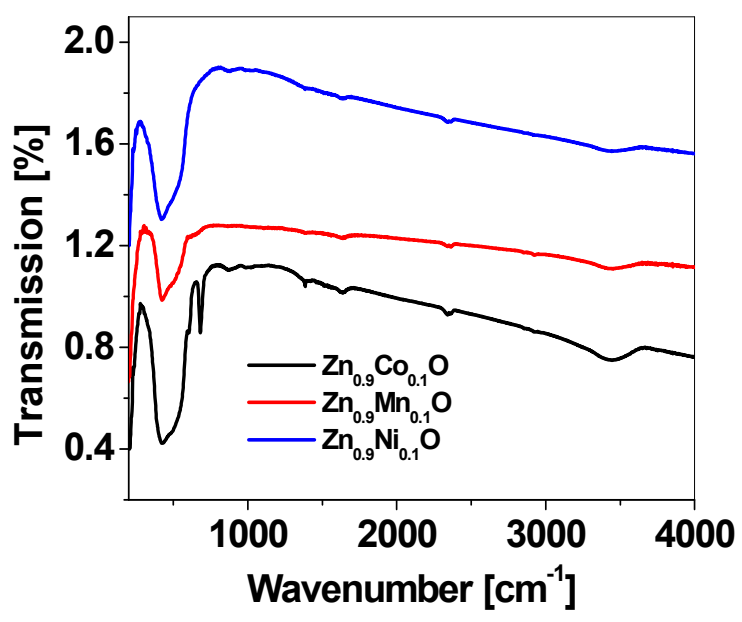

Figure 3: IR spectra of $\mathrm{Zn}_{0.9} \mathrm{Mn}_{0.1} \mathrm{O}, \mathrm{Zn}_{0.9} \mathrm{Co}_{0.1} \mathrm{O}$ and $\mathrm{Zn}_{0.9} \mathrm{Ni}_{0.1} \mathrm{O}$ nanoparticles

Figure. 4 shows the room temperature magnetization measurements for $\mathrm{Zn}_{0.9} \mathrm{Mn}_{0.1} \mathrm{O}, \quad \mathrm{Zn}_{0.9} \mathrm{Co}_{0.1} \mathrm{O}$ and $\mathrm{Zn}_{0.9} \mathrm{Ni}_{0.1} \mathrm{O}$ nanoparticles. Generally these materials were observed to be paramagnetic or antiferromagnetic at room temperature. These materials shows ferromagnetic properties when they are in thin film form. Often, the presence of secondary phases might contribute for achieving the ferromagnetic properties in the bulk, nano and in thin films. As observed from Figure 4, all the $\mathrm{M}-\mathrm{H}$ curves shows the room temperature ferromagnetic behavior owing to very small magnetization values. Probably the Curie temperature $\left(T_{C}\right)$ of these materials might be above room temperature (Huang et al., 2009). The $\mathrm{M}-\mathrm{H}$ curves are very narrow and the magnetization values are very small. Finding the remanence and coercivity was not possible as there are no clear hysteresis loops. The ferromagnetic behavior in the synthesized samples may be due to the several reasons such as, the synthesis technique, synthesis environment, annealing temperature, particle size etc. In the case of TM doped $\mathrm{ZnO}$ thin films, defects can be created in order to achieve room temperature ferromagnetic properties (Hong et al., 2005 and Hong et al., 2007). Rabi et al., (2007) for $\mathrm{Co}$ and $\mathrm{Mn}$ doped $\mathrm{ZnO}$ nanopowders, the ferromagnetic properties were not due to secondary phases. The room temperature ferromagnetic properties in TM doped $\mathrm{ZnO}$ was observed due to carrier exchange interactions, the large variation in the carrier concentration and magnetic properties were observed to depend on the synthesis technique (Ghosh et al., 2005). Also, the origin of 
Tamirat Tibebu et al.,

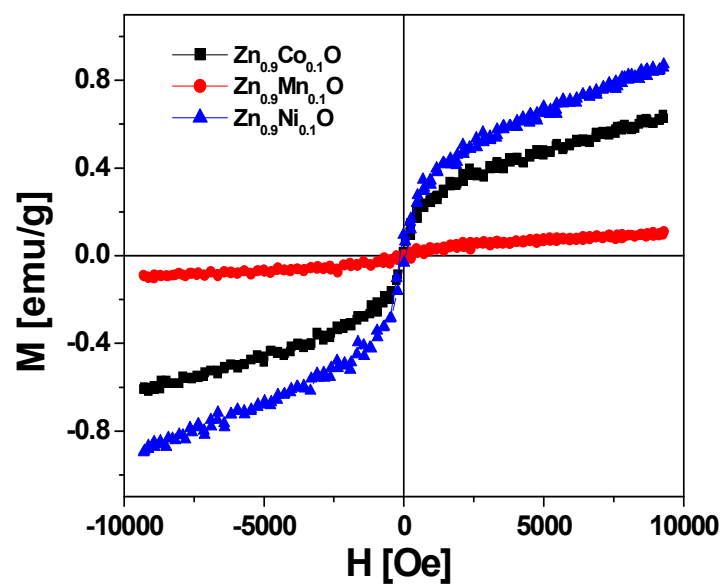

Figure 4: $\mathrm{M}-\mathrm{H}$ curves for $\mathrm{Zn}_{0.9} \mathrm{Mn}_{0.1} \mathrm{O}, \mathrm{Zn}_{0.9} \mathrm{Co}_{0.1} \mathrm{O}$ and $\mathrm{Zn}_{0.9} \mathrm{Ni}_{0.1} \mathrm{O}$ nanoparticles

in the samples is not fully understood. Further experiments will be carried in near future and its results will be reported in detail.

\section{CONCLUSIONS}

TM doped ZnO nanocrystals were synthesized using co-precipitation technique. X-ray diffraction patterns shows the formation of $\mathrm{TM}$ doped $\mathrm{ZnO}$ nanoparticles having particle size around $10 \mathrm{~nm}$. IR measurements showed the structural formation due to TM doping in $\mathrm{ZnO}$. The room temperature magnetic measurements for $\mathrm{Mn}$, Co, Ni doped showed the weak ferromagnetic properties.

\section{Conflict of Interest}

Authors declared no conflict of interest.

\section{REFERENCES}

Berhanu, H., Raghavender, A.T., Kebede, L., Anjaneyulu, T. (2014). Ferromagnetic Behavior in Zinc Ferrite Nanoparticles Synthesized using Co-precipitation Technique. Science Technology Arts and Research Journal 3: 85-88.

Ghosh, S., Sih, V., Lau, W.H., Awschalam, D.D., Baes, S-Y., Wang, S., Vaidya, S., Chapline, G. (2005). Room
Sci. Technol. Arts Res. J., Jan-March 2015, 4(1): 88-90 temperature spin coherence in $\mathrm{ZnO}$. Applied Physics Letters 86: 232507 (1-3).

Hong, N.H., Sakai, J., Brize, V. (2007). Observation of ferromagnetism at room temperature in $\mathrm{ZnO}$ thin films. Journal of Physics: Condensed Matter. 19: 036219 (1-6).

Hong, N.H., Sakai, J., Brize, V., (2005). Mn doped and (Mn, Co)- doped $\mathrm{ZnO}$ thin films: Does $\mathrm{Cu}$ doping indeed play a key role in the ferromagnetism. Applied Physics Letter 86: 082505 (1-3).

Hong, N.H., Sakai, J., Huong, N.T., Poirot, N., Ruyter, A. (2005). Role of defects in tuning ferromagnetism in dilute magnetic oxide thin films. Physical Review B 72: 045336 (1-5).

Huang, X., Li, G., Cao, B., Wang, M., Hao, C. (2009). Morphology Evolution and CL Property of Ni-Doped Zinc Oxide. Nanostructures with Room-Temperature Ferromagnetism. Journal of Physical Chemistry C 113: 4381-4385.

Martinez, B., Sandiumenge, F., Balcells LI., Arbiol, J., Sibiende, F., Monty, C. (2005). Structural and magnetic properties of Co doped ZnO nanopartiles. Physical Review B 72:165202-8.

Pearton S. J., Abernathy C. R., Norton D. P., Hebard A. F., Park D., Boather L. A., Budai J. D. (2003). Advances in wide bandgap materials for semiconductor spintronics. Material Science and Engineering R. 40: 137 - 168.

Raghavender, A.T., Nguyen Hoa Hong. (2011). Dependence of Néel temperature on the particle size of $\mathrm{MnFe}_{2} \mathrm{O}_{4}$. Journal of Magnetism and Magnetic Materials 323: 21452147.

Rubi, D., Calleja, A., Arbiol, J., Capdevila, X.G., Segarra M., Aragones Li., Fontcubbera, J. (2007). Structural and magnetic properties of $\mathrm{ZnO}: \mathrm{TM}$ (TM: Co, Mn) nanopowders. Journal of Magnetism and Magnetic Materials 316: e211 - e214.

Sato, K., Katayama -Yoshida, H. (2002). First principle materials design for semiconductor spintronics. Semiconductor Science and Technology 17: 357 - 376.

Wang, L., Muhammed, M. (1999). Synthesis of zinc oxide nanoparticles with controlled morphology. Journal of Material Chemistry 9: 2871-2878. 